\title{
Higher frequency of cagA EPIYA-C Phosphorylation Sites in $H$. pylori strains from first-degree relatives of gastric cancer patients
}

Dulciene MM Queiroz ${ }^{2}$, Cícero ISM Silva', Maria HRB Goncalves ${ }^{1}$, Manuel B Braga-Neto ${ }^{1}$, Andréa BC Fialho ${ }^{1}$, André MN Fialho ${ }^{2}$, Gifone A Rocha ${ }^{2}$, Andreia MC Rocha ${ }^{2}$, Sérgio A Batista ${ }^{2}$, Richard L Guerrant ${ }^{3}$, Aldo AM Lima ${ }^{4}$ and Lucia LBC Braga ${ }^{1 *}$

\begin{abstract}
Background: To evaluate the prevalence of more virulent H. pylori genotypes in relatives of gastric cancer patients and in patients without family histories of gastric cancer.

Methods: We evaluated prospectively the prevalence of the infection by more virulent $H$. pylori strains in 60 relatives of gastric cancer patients comparing the results with those obtained from 49 patients without family histories of gastric cancer. H. pylori status was determined by the urease test, histology and presence of $\mathrm{H}$. pylori ureA. The cytotoxin associated gene (cagA), the cagA-EPIYA and vacuolating cytotoxin gene (vacA) were typed by PCR and the cagA EPIYA typing was confirmed by sequencing.

Results: The gastric cancer relatives were significant and independently more frequently colonized by $\mathrm{H}$. pylori strains with higher numbers of CagA-EPIYA-C segments $(\mathrm{OR}=4.23,95 \% \mathrm{Cl}=1.53-11.69)$ and with the most virulent $\mathrm{s} 1 \mathrm{~m} 1$ vacA genotype $(\mathrm{OR}=2.80,95 \% \mathrm{Cl}=1.04-7.51)$. Higher numbers of EPIYA-C segments were associated with increased gastric corpus inflammation, foveolar hyperplasia and atrophy. Infection by s $1 \mathrm{~m} 1$ vacA genotype was associated with increased antral and corpus gastritis.
\end{abstract}

Conclusions: We demonstrated that relatives of gastric cancer patients are more frequently colonized by the most virulent $H$. pylori cagA and vacA genotypes, which may contribute to increase the risk of gastric cancer.

Keywords: Helicobacter pylori, Gastric cancer, H. pylori CagA-EPIYA, H. pylori/vacA

\section{Background}

Helicobacter pylori, a Gram-negative bacterium that infects the stomach of approximately half the world's population, is associated with the development of gastroduodenal diseases including gastric and duodenal peptic ulcer, distal gastric adenocarcinoma and mucosaassociated lymphoid tissue lymphoma [1]. It is estimated that individuals infected with $H$. pylori have more than two-fold increased risk of developing gastric cancer compared with non-infected ones [2] although Japanese

\footnotetext{
* Correspondence: lucialib@terra.com.br

${ }^{1}$ Clinical Research Unity - Department of Internal Medicine, University Hospital Walter Cantídio - Federal University of Ceará, P.O. Box: 60430270, Fortaleza, Ceará, Brazil

Full list of author information is available at the end of the article
}

studies might suggest that nearly all gastric cancer is related to Helicobacter [3]. Why only 1 to $5 \%$ of $H$. pyloriinfected persons develop gastric cancer remains unknown and it seems to depend on the relationship between environmental, host genetics and bacterial virulence factors.

Several studies have shown an increased risk of developing gastric cancer in relatives of patients with the disease [2,4]. Similarly, an increased prevalence of precancerous gastric lesions has been observed in relatives of gastric cancer patients [5]. However, molecular mechanisms by which $H$. pylori triggers the process leading to gastric carcinoma remain largely unknown.

The most investigated $H$. pylori virulence determinant, the cag-PAI (cytotoxin associated gene pathogenicity island), encodes a type IV secretion system (T4SS) that is responsible for the entrance of an effector protein, 
CagA, into host gastric epithelial cells [6,7]. Once translocated, CagA localizes to the inner surface of the plasma membrane where it is phosphorylated on the tryrosine residues within phosphorylation motifs in carboxy-terminal variable region of the protein by multiple members of the src-family tyrosine kinases. Once phosphorylated, CagA forms a physical complex with SHP-2 phosphatase and triggers abnormal cellular signals, which enhance the risk of damaged cells acquiring precancerous genetic changes $[8,9]$.

The phosphorylation motifs, defined as a sequence of five amino acids (Glu-Pro-Ile-Tyr-Ala), are classified as EPIYA-A, EPIYA-B, EPIYA-C and EPIYA-D, according to amino acid sequences flanking the motifs. CagA proteins nearly always possess EPIYA-A and -B segments, that are followed by none, one, two or three $C$ segments in strains circulating in the Western countries, or a D segment, in East Asia strains $[10,11]$. It has also been shown that infection with CagA strains having high number of EPIYA-C segments imparts a greater risk of precancerous gastric lesions and cancer [12-15].

Another virulence factor of $H$. pylori is a protein known as vacuolating cytotoxin A (VacA), which causes cytoplasmatic vacuolization in gastric epithelial cells, increasing the plasma cell and mitochondrial membrane permeability leading to apoptosis. The production of the cytotoxin is associated with the cag-PAI but depends on the $v a c \mathrm{~A}$ genotype [16-18]. The $v a c \mathrm{~A}$ is a polymorphic gene with two main signal region genotypes $\mathrm{s} 1$ and $\mathrm{s} 2$, and two different alleles in the mid region of the gene named $\mathrm{m} 1$ and $\mathrm{m} 2$. Infection with strains possessing the $\mathrm{s} 1 \mathrm{~m} 1$ genotype has been associated with precancerous gastric hypochlorhydria [17] and gastric carcinoma [19].

In a recent study conducted in Fortaleza, Northeastern, Brazil, in an area of high prevalence of gastric cancer and $H$. pylori infection, our group has shown a high prevalence of either pangastritis or precancerous lesions in relatives of gastric cancer patients infected with $H$. pylori [20].

Furthermore, Argent et al., (2008) observed an association between $v a c \mathrm{~A} s 1 \mathrm{~m} 1$ genotype of $H$. pylori strains and low gastric acid secretion in first-degree relatives of gastric cancer patients from Scotland [21]. Otherwise, the authors did not find associations between CagA positive status and or number of tyrosine phosphorylated motifs and gastric lesions in that population.

Since geographical differences have been observed among studies that evaluated association between $H$. pylori virulence factors and diseases, the aim of this crosssectional prospective study was to evaluate the CagA EPIYA motifs of $H$. pylori strains in first-degree relatives of gastric cancer patients comparing the results with those obtained from a control group composed of subjects with no family history of gastric cancer. Because the s $1 \mathrm{~m} 1$ genotype of the vacA $H$. pylori was seen to be more frequently observed in the strains of gastric cancer patients, we also evaluated the $v a c \mathrm{~A}$ mosaicism in the strains.

\section{Methods}

The study was approved by the Ethical Committee of Research of the University of Ceará, and informed consent was obtained from each subject.

\section{Patients}

Sixty H. pylori-positive first-degree relatives [42 female; mean age $40.42 \pm 11.80$; (4 brothers and 13 sisters; mean age $56.24 \pm 11.80$ years, 14 sons and 29 daughters; mean age $34.51 \pm 7.66)$ ] of gastric cancer patients from outpatient follow-up at Walter Cantídio Hospital were invited to participate. The control group was composed of 49 (32 female; mean age $43.20 \pm 12.59$ ) $\mathrm{H}$. pylori-positive patients who concurrently underwent upper gastrointestinal endoscopy for investigation of dyspepsia at the same Hospital. They did not have family history of gastric cancer, and were social class matched with the study group. Patients with history of gastric surgery, active gastrointestinal bleeding, use of steroids, immunosuppressive drugs, NSAIDs, proton pump inhibitors or who were treated for $H$. pylori eradication were excluded from the study. Relatives and controls were not included if they were under 18 or above 81 years old.

\section{Biopsy fragment collection}

Gastric fragments were obtained during endoscopy from five different sites as recommended by the Updated Sydney System for classification of gastritis [22]. Additionally, two fragments were collected from the antral mucosa for the rapid urease test and for DNA to investigate the presence of $H$. pylori genes. H. pylori infection was confirmed by positive results in at least two tests including a rapid urease test, histological analysis and presence of ureA gene of $H$. pylori.

\section{Histology}

Endoscopic biopsy samples of the gastric mucosa were fixed in 10\% formalin and embedded in paraffin wax, and 4- $\mu \mathrm{m}$-sections were stained with hematoxylin-eosin for routine histology. Gastritis was classified according to the Updated Sydney system. The samples of the gastric mucosa were also stained with Giemsa for detection of $H$. pylori.

\section{DNA extraction}

The antral gastric DNA was extracted using the QIAmp (QIAGEN, Hilden, Germany) kit according to the manufacturer's recommendations with minor modifications [23]. The DNA concentration was determined by 
spectrophotometry using NanoDrop 2000 (Thermo Scientific, Wilmington, NC) and stored at $-20^{\circ} \mathrm{C}$ until use.

The presence of $H$. pylori specific ureA gene was evaluated according to methodology reported by Clayton et al., [24]. The standard Tx30a H. pylori strain was used as a positive control, and an Escherichia coli strain and distilled water were both used as negative controls.

The thermocycler GeneAmp PCR System 9700 (Applied Biosystems, Foster City, CA) was used for all reactions. The amplified products were electrophoresed in $2 \%$ agarose gel, stained with ethidium bromide, and analyzed in an ultraviolet light transilluminator.

\section{vacA and cagA detection}

PCR amplification of the vacA signal sequence and mid region was performed by using the oligonucleotide primers described by Atherton et al., [15]. The strains were initially classified as type $\mathrm{s} 1$ or $\mathrm{s} 2$ and type $\mathrm{m} 1$ or $\mathrm{m} 2$. All $H$. pylori strains with s1 were further characterized into s1a, s1b or s1c $[25,26]$.

The cagA gene was amplified by means of two previously described set of primer pairs $[27,28]$. A H. pylori strain from our collection (1010-95), known to be vacA s1m1 and cagA-positive, was used as a positive control, and the s2m2 vacA genotype, cagA-negative standard Tx30a $H$. pylori strain and distilled water were both used as negative controls. The $H$. pylori strains were considered to be cagA-positive when at least one of the two reactions was positive.

\section{Amplification of the $3^{\prime}$ variable region of cagA}

For the PCR amplification of the 3' variable region of the cagA gene (that contains the EPIYA sequences), 20 to 100 ng of DNA were added to 1\% Taq DNA polymerase buffer solution ( $\mathrm{KCl} 50 \mathrm{mM}$ and Tris- $\mathrm{HCl} 10 \mathrm{mM}, \mathrm{pH}, 8.0), 1.5$ $\mathrm{mM} \mathrm{MgCl} 2,100 \mu \mathrm{M}$ of each deoxynucleotide, $1.0 \mathrm{U}$ Platinum Taq DNA polymerase (Invitrogen, São Paulo, Brazil), and 10 pmol of each primer, for a total solution volume of $20 \mu \mathrm{L}$. The primers used were previously described by Yamaoka et al. [29]. The reaction conditions were: $95^{\circ} \mathrm{C}$ for 5 minutes, followed by 35 cycles of $95^{\circ} \mathrm{C}$ for 1 minute, $50^{\circ} \mathrm{C}$ for 1 minute, and $72^{\circ} \mathrm{C}$ for 1 minute, ending with $72^{\circ} \mathrm{C}$ for 7 minutes. The reaction yielded products of 500 to 850 bp as follows: EPIYA-AB: 500 bp; EPIYA-ABC: 640 bp; EPIYA-ABCC: 740 bp and EPIYA-ABCCC: 850 bp (Figure 1).

We also used the method described by Argent et al. [30] for the PCR amplification of the 3' variable region of the cagA gene that contains the EPIYA sequences in order to improve the accuracy of our results.

\section{Sequencing of the $3^{\prime}$ variable region of cagA}

A subset of samples was randomly selected for sequencing in order to confirm the PCR results. PCR products were purified with the Wizard SV Gel and PCR Cleanup System (Promega, Madison, MI) according to the manufacturer's recommendations. Purified products were sequenced using a BigDye Terminator v3.1 Cycle Sequencing kit in an ABI 3130 Genetic Analyzer (Applied Biosystems, Foster City, CA). The sequences obtained were aligned using the CAP3 Sequence Assembly Program (available from: http://pbil.univ-lyon1.fr/cap3. php). After alignment, nucleotide sequences were transformed into amino acid sequences using the Blastx program (available from: http://blast.ncbi.nlm.nih.gov/ Blast.cgi) and compared to sequences deposited into the GenBank (http://www.ncbi.nlm.nih.gov/Genbank/).

\section{Statistical analysis}

Data were analyzed with SPSS (Inc. Chicago, IL), version 17.0. The risk of relatives of gastric carcinoma to be infected by more virulent strains, with increased number of EPIYA-C motifs and s1m1 vacA genotype, was initially evaluated in univariate analysis. For that, cagA strains were stratified in those possessing at least one EPIYA-C segment and those with more than one EPIYA-C segment and the most virulent vacA s1m1 genotype was compared with s1m2 plus s2m2. Variables with a $p$-value less-than or equal to 0.25 were included in the final model of logistic regression, controlling for the influences of age and sex. Odds Ratio (OR) and 95\% confidence intervals (CI) were calculated. The logistic model fitness was evaluated with the Hosmer-Lemeshow test [31]. Association of the number of EPIYA-C segments and the presence of vacA virulent genotypes with the degree of gastric inflammation, atrophy and intestinal metaplasia was done by the two-tailed Mann-Whitney Test. The level of significance was set at a $p$ value $\leq 0.05$.

\section{Results}

The presence of $H$. pylori specific ureA gene was detected in the gastric mucosa of all 109 studied subjects.

\section{cagA status of the patients}

cagA positivity was observed in the gastric fragments from $51(85.00 \%)$ of 60 gastric cancer relatives and in those from $43(87.76 \%)$ of 49 controls, without difference between the groups $(p=0.68 ; \mathrm{OR}=1.26,95 \% \mathrm{CI}=0.37-4.40)$.

\section{The number of EPIYA-C segments}

The EPIYA pattern of all cagA-positive strains from both relatives of gastric cancer patients and controls were successfully typed. The Yamaoka methodology allowed the detection of mixed strain infection. The concordance between the methods used was almost $100 \%$. The results were confirmed by sequencing of the 3' variable region of cagA in 30 randomly selected PCR products. 
Ref.26695 KELNEK-FKNFNHNNN-GLKNST-----EPIYAKYNKKKTGQYASPEEPIYTQYAKKYNAKIDRL NQIASGLGGYGQAFG 2 KELNEK-FKNFNNNNNXGLKNGG-----EPIYAQYNKKKTGQYASPEEPIYAQYAKKYNAKIDRLNQIASGLGGYGQRAG

3 KELNAKLFGNFNNNNNNGLKNST-----EPIYAKVNKKKSGQRASPEEPIYAQYAKKYNAKIDRLNQIASGLGGYGQRAG

4 KELNE--IKNFNHNNN-GLKNST-----EPIYAKYNKKKTGOYASPEEPIYTOYAKKYNAKIDRLNOIARGLGGYGOARG

5 KELNAKLFGNFNHNNNNGLKN-------EPIYAQYNKKKAGQYASPEEPIYAQYAKKYNAKIDRLNQIASGLGGYGQARG

6 KELNEK-FKNFNNNNN-GLKNGKDKGPEEPIYAQYNKKKTGQYASPEEPIYAQYAKKYTQKIDQLNQAASGFGGYRQR-G

7 KELNEK-FKNFNNNNN-GLKNST-----EPIYAQYNKKKTGQYASPEEPIYAQYAKKYNAKIDQLNQARSGFGGYGQRG-

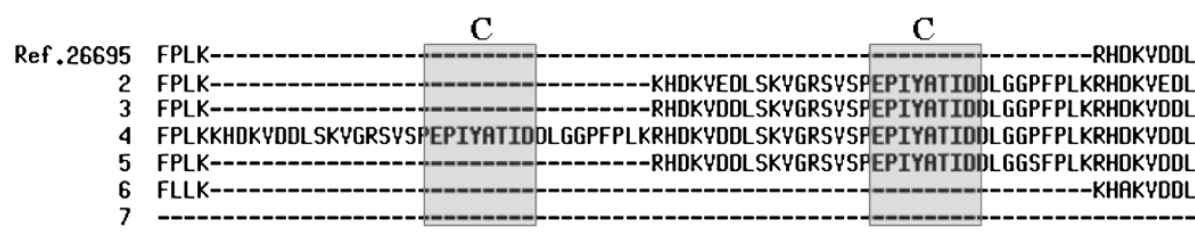

C

Ref.26695 SKYGLSASPEPIYATIDDLGGPFPLKRHDKYDDLSKYGRSRNQELAQKIDNLNQAYSEAKA - ABC 2 SKYRRSYSPEPIYATIDDLGGPFPLKRHDKYEDLGKYGLSGNQELAQKIDNLNQAYSEAKA - ABCC

3 SKYGRSYSPEPIYATIDDLGGPFPLKRHDKYDDLSKYGLSR--OLKONIDNLNOAYSEAKA - ABCC

4 SKYGRSYSPEPIYATIDDLGGPFPLKRHDKYDDLSKYGLSRGQELDRKIDNLNQAYSEAKA - ABCCC

5 SKYGRSYSPEPIYATIDDLGGSFPLKRHDKYDDLSKYGLSRNQELRQKIDNLNQAYSERKA - ABCC

6 SKYGQSASPEPIYATIDELGGPFPLKRHDKYDDLSKYGLSREQQLAQKIDNLSQAYSEAKY - ABC

7 - AB

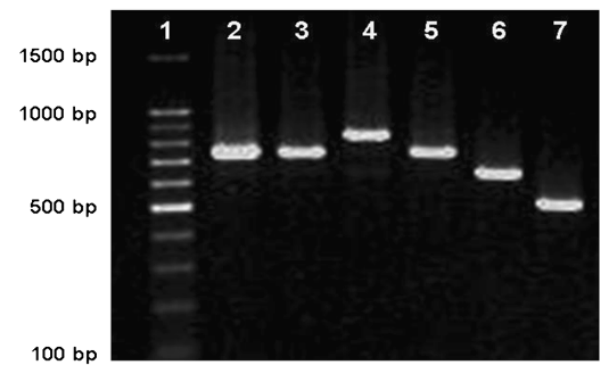

Figure 1 Electrophoresis of representative samples with different CagA EPIYA patterns seen in relatives of gastric cancer patients and controls. Columns 2, 3 e 5: EPIYA-ABCC (740 bp); column 4: EPIYA-ABCCC (850 bp); column 6: EPIYA-ABC (640 bp) and Column 7: EPIYA-AB (500 bp). Upper: partial alignment of amino acid sequencing of the carboxy-terminal CagA strains and a reference strain (H. pylori 26695).

Four patterns of EPIYA motifs were found: $A B, A B C$, ABCC, and ABCCC. No Asian EPIYA-D motif was observed. The distribution of the EPIYA genotypes is shown in the Table 1.

\section{vacA mosaicism distribution}

The distribution of $v a c \mathrm{~A}$ genotypes is shown in the Table 2. In 59 cases $(54.13 \%)$ the vacA genotype was

Table 1 Distribution of EPIYA genotypes in the gastric cancer relatives $(n=51)$ and controls $(n=43)$ colonized by a cagA-positive strains

\begin{tabular}{lccc}
\hline EPIYA Genotype & $\begin{array}{c}\text { Control } \\
\text { group } \mathbf{n} \\
\text { (\%) }\end{array}$ & \multicolumn{2}{c}{ Gastric cancer relatives } \\
\cline { 3 - 4 } & $03(7.0)$ & $\begin{array}{c}\text { Siblings } \\
\mathbf{n}(\%)\end{array}$ & $\begin{array}{c}\text { offspring } \\
\mathbf{n}(\%)\end{array}$ \\
\hline EPIYA-AB & $32(74.4)$ & $09(60.0)$ & 0 \\
EPIYA-ABC & $07(16.3)$ & $04(26.7)$ & $12(33.2)$ \\
EPIYA-ABCC & $01(2.3)$ & $01(6.7)$ & $02(5.6)$ \\
EPIYA-ABCCC & 0 & $01(6.7)$ & $02(5.6)$ \\
EPIYA-ABC+ABCC & $43(100.0)$ & $15(100.0)$ & $36(100.0)$ \\
Total & & &
\end{tabular}

$\mathrm{s} 1 \mathrm{~m} 1$, in $35(32.11 \%)$ it was $\mathrm{s} 1 \mathrm{~m} 2$ and $6(5.50 \%) \mathrm{s} 2 \mathrm{~m} 2$. In three $(2.75 \%)$ cases two vacA genotypes were observed and in six (5.50\%) only the signal sequence (s1) was detected. DNA was not enough to genotype $\mathrm{m}$ allele in four among these cases and in two, $m$ was not typable. In all cases with s1 strains they were genotyped as $\mathrm{s} 1 \mathrm{~b}$, except in one case who was colonized by s1a and s1b strains.

Table 2 Distribution of vacA alleles of $\boldsymbol{H}$. pylori strains of relatives of gastric cancer patients $(n=55)$ and control group $(n=48)$

\begin{tabular}{|c|c|c|c|}
\hline \multirow{2}{*}{$\begin{array}{c}\text { vacA } \\
\text { Genotypes }{ }^{1}\end{array}$} & \multirow{2}{*}{$\begin{array}{l}\text { Control } \\
\text { group } n \\
(\%)\end{array}$} & \multicolumn{2}{|c|}{ Gastric cancer relatives } \\
\hline & & $\begin{array}{l}\text { Siblings } \\
\mathrm{n}(\%)\end{array}$ & $\begin{array}{c}\text { Offspring } \\
\text { n (\%) }\end{array}$ \\
\hline s1m1 & $23(47.92)$ & $10(66.67)$ & $26(65.00)$ \\
\hline $\mathrm{s} 1 \mathrm{~m} 2$ & $21(43.75)$ & $04(26.67)$ & $10(25.00)$ \\
\hline $\mathrm{s} 2 \mathrm{~m} 2$ & $03(6.25)$ & $01(6.67)$ & $02(5.00)$ \\
\hline Mixed $^{2}$ & 01 (2.08) & 0 & $02(5.00)$ \\
\hline Total & $48(100)$ & $15(100)$ & $40(100)$ \\
\hline
\end{tabular}

Only vacA s1 genotype was identified in 6 cases ( 1 control, 2 siblings and 3 offsprings of gastric cancer relatives); ${ }^{2}$ Mixed infection by $\mathrm{s} 1 \mathrm{~m} 1$ and $\mathrm{s} 2 \mathrm{~m} 2$ or $\mathrm{s} 1 \mathrm{~m} 1$ and $\mathrm{s} 1 \mathrm{~m} 2$ (two cases). 
Infection by the most toxigenic $v a c \mathrm{~A}$ genotype $(\mathrm{s} 1 \mathrm{~m} 1)$ was more frequently observed in the gastric cancer relatives (65.45\%) than in the controls (47.92\%). When $\mathrm{s}$ and $\mathrm{m}$ alleles were individually evaluated, no difference in the frequency of s1 allele was observed between the groups, but $\mathrm{m} 1$ allele was more frequently observed in the gastric cancer relatives.

Association among the number of EPIYA-C motifs and the vacA $s 1 \mathrm{~m} 1$ genotype and family history of gastric cancer The relatives of gastric cancer patients were significantly and independently more frequently colonized by $H$. pylori strains with increased number CagA-EPIYA-C segments and with the most virulent $\mathrm{s} 1 \mathrm{~m} 1$ vacA genotype even after adjustment for age and gender (Table 3).

No difference was observed between siblings and offspring in respect to infection by strains containing an increased number of EPIYA-C motifs $(p=0.98$; OR $=$ $1.20,95 \% \mathrm{CI}=0.30-4.86)$ and the $v a c \mathrm{~A}$ genotypes $\mathrm{s} 1 \mathrm{~m} 1$ vs. $\mathrm{s} 1 \mathrm{~m} 2$ and $\mathrm{s} 2 \mathrm{~m} 2(p=0.84 ; \mathrm{OR}=0.92,95 \% \mathrm{CI}=0.22-$ 3.97) as shown in the Tables 1 and 2.

\section{Associations among the number of EPIYA-C segments} and vacA genotypes and gastric histological alterations The degrees of corpus gastritis $(p=0.04)$, antrum activity $(p=0.01)$ and corpus activity were significantly higher in the relative of gastric cancer patients than in the control group.

A higher number of EPIYA-C segments was associated with gastric corpus inflammation $(p=0.04)$, gastric corpus foveolar hyperplasia $(p=0.05)$ and gastric corpus atrophy $(p=0.05)$ in the relatives of gastric cancer patients.

Infection by the most virulent $v a c \mathrm{~A} \mathrm{~s} 1 \mathrm{~m} 1$ genotype was associated with more marked antral $(p=0.03)$ and corpus $(p=0.05)$ gastritis, when both groups were evaluated together.

\section{Discussion}

H. pylori infection is recognized as the most important risk factor for distal gastric cancer. Furthermore, the increased rates of the disease in relatives of gastric

Table 3 Covariables associated with gastric cancer in the first-degree relatives of gastric cancer patients in comparison with subjects without family history of gastric cancer

\begin{tabular}{lccccc}
\hline \multicolumn{1}{c}{ Variables } & Univariate analysis & & \multicolumn{3}{c}{ Multivariate analysis } \\
\cline { 2 - 3 } \cline { 5 - 6 } & $\boldsymbol{p}$ & & OR & $\mathbf{9 5 \%} \mathrm{Cl}$ & $\boldsymbol{p}$ \\
\hline Gender & 0.27 & & - & - & - \\
Age & 0.30 & & - & - & - \\
$>1$ EPIYA-C motif & 0.01 & & 4.23 & $1.53-11.69$ & 0.006 \\
s1m1 vacA allele & 0.17 & & 2.80 & $1.04-7.51$ & 0.04 \\
\hline
\end{tabular}

The Hosmer-Lemeshow test was fit ( 8 degrees of freedom, $p>0.20$, with 10 steps). cancer points to host genetics and/or share of the most H. pylori virulence strains as risk factors.

In this study, we demonstrated that relatives of gastric cancer patients are more frequently colonized by $H$. pylori strains with the most virulent vacA genotype, s1m1, and by CagA-positive strains possessing a higher number of EPIYA-C segments than the $H$. pylori strains of the patients without a family history of the disease.

Although no previous study has demonstrated that gastric cancer relatives are more frequently colonized by more virulent $H$. pylori strains, infection by vacA $\mathrm{s} 1 \mathrm{~m} 1$ was associated with low gastric acid secretion, a precancerous condition, in first-degree relatives of Scottish gastric cancer patients [21]. Otherwise, no association between the gastric acid secretion and the number of CagA EPIYA-C segments was observed by the authors [21].

CagA is the first bacterial oncoprotein to be identified [32]. The protein is delivered into the gastric epithelial cell through a bacterial T4SS and localizes to the inside of the cell membrane, where it is phosphorylated by host cell kinases. Upon phosphorylation, the EPIYA-C segment interacts with SHP-2 phosphatase, a bona fide oncoprotein that is associated with a series of human cancers. The higher the number of EPIYA-C segments, the higher the affinity for SHP-2 which is required for a full activation of ERK/MAPK pathway.

Infection with CagA strains possessing higher number of EPIYA-C segments has been associated with precancerous gastric lesions and gastric cancer in Caucasian [11-13,30] and Brazilian populations [15].

It is well established that $H$. pylori infection is predominantly acquired in childhood and that the infection often persists for life unless treated. Epidemiological data and genetic analysis of $H$. pylori strains have demonstrated that the strains are usually acquired within the family. In fact, infected mother and infected siblings are the main risk factors for the acquisition of the infection $[33,34]$ and genetic fingerprint methods have demonstrated genetic homogeneity in the $H$. pylori strains within the families. Based on these findings and the results of the present study, we may hypothesize that first degree relatives of gastric cancer patients may share more virulent $H$. pylori strains that may increase the risk of gastric cancer.

As noted above, first-degree relatives of gastric cancer patients also share the same or similar genetic background that may increase the risk of gastric cancer. Polymorphisms in genes coding pro-inflammatory cytokines, such as interleukin 1 beta (IL-1 $\beta$ ), interleukin-1 receptor antagonist (IL1Ra) and tumor necrosis factor-alpha (TNF- $\alpha$ ) are accepted as risk factors of gastric cancer, depending on the geographic region [35-39]. It has also been demonstrated that having increasing number of pro-inflammatory genotypes [36,37], as well as a 
concomitant infection by more virulent $H$. pylori strains progressively increases the risk of gastric precancerous lesions and cancer [39].

\section{Conclusions}

In conclusion, we demonstrated that relatives of gastric cancer patients are more frequently colonized by the most virulent $H$. pylori cagA and vacA genotypes, which may, in addition to human genetic predispositions, further increase their risk of gastric cancer, thus providing additional reasons to better understand these infections and perhaps their targeted eradicative treatment.

\section{Competing interests}

The authors declare no-confllict-of-interest.

\section{Authors' contributions}

DMMQ supervised laboratory work and analyzed the data critical writing and reviewing manuscript. $S A B$ performed DNA extraction, $P C R$ and sequencing and statistical analysis, GAR and AMCR, participated in implementation of the study and wrote the manuscript, CISMS and MHB performed DNA extraction, PCR and database management, MBN, ABF and AMN participated in implementation of the study, data collection, database management and statistical analysis. RLG and AAML performed critical analysing of the data and reviewing of the manuscript. LLBCB participated in conception, design, implementation, coordination of the study and contributed to manuscript writing critical writing and reviewing. All authors have read and approved the final version of the manuscript.

\section{Acknowledgements}

This work was supported by Instituto Nacional de Ciências e Tecnologia em Biomedicina do Semiárido Brasileiro (INCT) and CNPq, Brazil. We are grateful to Professor Barry J Marshall for critical reading of the manuscript. Results of the study was presented as abstract at Digestive Disease Week, DDW 2011, Chicago USA.

\section{Author details}

${ }^{1}$ Clinical Research Unity - Department of Internal Medicine, University Hospital Walter Cantídio - Federal University of Ceará, P.O. Box: 60430270 , Fortaleza, Ceará, Brazil. ${ }^{2}$ Laboratory of Research in Bacteriology, Federal University of Minas Gerais, Belo Horizonte, Minas Gerais, Brazil. ${ }^{3}$ Center for Global Health, University of Virginia, Charlottesville, VA, USA. ${ }^{4}$ Department of Physiology and Pharmacology, Federal University of Ceará, Fortaleza, Ceará, Brazil.

Received: 29 February 2012 Accepted: 8 August 2012

Published: 14 August 2012

\section{References}

1. Parsonnet J, Friedman GD, Vandersteen DO: Helicobacter pylori and the risk of gastric carcinoma. N Engl J Med 1991, 25:1127-1131.

2. Brenner H, Arndt V, Stürmer T, Stegmaier C, Ziegler H, Dhom G: Individual and joint contribution of family history and Helicobacter pylori infection to the risk of gastric carcinoma. Cancer 2000, 88:274-279.

3. Uemura N, Okamoto S: Effect of Helicobacter pylori eradication on subsequent development of cancer after endoscopic resection of early gastric cancer in Japan. Gastroenterol Clin North Am 2000, 29:819-827.

4. Chang YW, Han YS, Lee DK, Kim HJ, Lim HS, Moon JS, et al: Role of Helicobacter pylori infection among offspring or siblings of gastric cancer patients. Int J Cancer 2002, 101:469-474.

5. Jablonska M, Chlumska A: Genetic factors in the development of gastric precancerous lesions - a role of Helicobacter pylori? Int J Cancer 2001, 95:477-481.

6. Segal ED, Cha J, Lo J, Falkow S, Tompkins LS: Altered states: Involvement of phosphorylated CagA in the induction of host cellular growth changes by Helicobacter pylori. Proc Natl Acad Sci USA 1999, 96:14559-14564.
7. Odenbreit S, Püls J, Sedlmaier B, Gerland E, Fischer W, Haas R: Translocation of Helicobacter pylori CagA into gastric epithelial cells by type IV secretion. Science 2000, 287:1497-1500

8. Higashi H, Tsutsumi R, Muto S, Sugiyama T, Azuma T, Asaka M, et al: SHP-2 tyrosine phosphatase as an intracellular target of Helicobacter pylori CagA protein. Science 2002, 295:683-686.

9. Naito M, Yamazaki T, Tsutsumi R, Higashi H, Onoe K, Yamazaki S, et al: Influence of EPIYA-repeat polymorphism on the phosphorylationdependent biological activity of Helicobacter pylori CagA. Gastroenterology 2006, 130:1181-1190.

10. Hatakeyama M: Oncogenic mechanisms of the Helicobacter pylori CagA protein. Nat Rev Cancer 2004, 4:688-694.

11. Argent $\mathrm{RH}$, Hale JL, El-Omar EM, Atherton JC: Differences in Helicobacter pylori CagA tyrosine phosphorylation motif patterns between western and East Asian strains, and influences on interleukin- 8 secretion. $J$ of Med Microb 2008, 57:1062-1067.

12. Yamaoka Y, El-Zimaity HMT, Gutierrez O, Figura N, Kim JK, Kodama T, et al: Relationship between the cagA 3 ' repeat region of Helicobacter pylori, gastric histology, and susceptibility to low pH. Gastroenterology 1999, 117:342-349.

13. Basso D, Zambon CF, Letley DP, Stranges A, Marchet A, Rhead JL, et al Clinical relevance of Helicobacter pylori cagA and vacA gene polymorphisms. Gastroenterology 2008, 135:91-99.

14. Sicinschi LA, Correa P, Peek RM, Camargo MC, Piazuelo MB, Romero-Gallo J, et al: CagA C-terminal variations in Helicobacter pylori strains from Colombian patients with gastric precancerous lesions. Clin Microbiol Infect 2010, 16:369-378.

15. Batista SA, Rocha GA, Rocha AM, Saraiva IE, Cabral MM, Oliveira RC, et al: Higher number of Helicobacter pylori CagA EPIYA C phosphorylation sites increases the risk of gastric cancer, but not duodenal ulcer. BMC Microbiol 2011, 11:61

16. Atherton JC, Cao P, Peek RM Jr, Tummuru MK, Blaser MJ, Cover TL: Mosaicism in vacuolating cytotoxin alleles of Helicobacter pylori. Association of specific vacA types with cytotoxin production and peptic ulceration. J Biol Chem 1995, 270:17771-177777.

17. Willihite DC, Blanke SR: Helicobacter pylori vauolating cytotoxin induces activation of the proapoptotic enters cells, localizes to the mithochondria and induces mithochondrial membrane permeability changes correlated to toxin channel activity. Cell Microbiol 2004, 6:143-154.

18. Yamasaki E, Wada A, Kumatori A, Nakagawa I, Funao J, Nakayama M, et al: Helicobacter pylori vacuolating cytotoxin induces activation of the proapoptotic proteins Bax and Bak, leading to cytochrome c release and cell death, independent of vacuolation. J Biol Chem 2006, 281:11250-11259.

19. Ashour AA, Magalhães PP, Mendes EN, Collares GB, de Gusmão VR, Queiroz DM, et al: Distribution of vacA genotypes in Helicobacter pylori strains isolated from Brazilian adult patients with gastritis, duodenal ulcer or gastric carcinoma. FEMS Immunol Med Microbiol 2002, 33:173-178.

20. Motta CR, Cunha MP, Queiroz DM, Cruz FW, Guerra EJ, Mota RM, et al: Gastric precancerous lesions and Helicobacter pylori infection in relatives of gastric cancer patients from northeastern Brazil. Digestion 2008, 78:3-8.

21. Argent RH, Thomas RJ, Aviles-Jimenez F, Letley DP, Limb MC, El-Omar EM, Atheton JC: Toxigenic Helicobacter pylori infection precedes hypochlorydria in cancer relatives, and $\mathrm{H}$. pylori evolves in these families. Clin Canc Res 2008, 14:2227-2235.

22. Dixon MF, Genta RM, Yardley JH, Correa P: Classification and grading of gastritis. The updated Sydney System. International Workshop on the Histopathology of Gastritis, Houston 1994. Am J Surg Pathol 1996, 20:1161-1181.

23. Monteiro MA, Chan KH, Rasko DA, Taylor DE, Zheng PY, Appelmelk BJ, et al: Simultaneous expression of type 1 and type 2 Lewis blood group antigens by Helicobacter pylori lipopolysaccharides. Molecular mimicry between $h$. pylori lipopolysaccharides and human gastric epithelial cell surface glycoforms. J Biol Chem 1998, 273:11533-11543.

24. Clayton CL, Kleanthous H, Coates PJ, Morgan DD, Tabaqchali S: Sensitive Detection of Helicobacter-pylori by Using Polymerase Chain-Reaction. J Clin Microbiol 1992, 30:192-200.

25. van Doorn L, Fiqueiredo C, Sanna R, Plaisier A, Schneeberger P, de Boer W, et al: Clinical relevance of the $\operatorname{cag} \mathrm{A}, \operatorname{vac} \mathrm{A}$, and iceA status of Helicobacter pylori. Gastroenterology 1998, 115:58-66.

26. Atherton JC, Cover TL, Wells RJ, Morales MR, Hawley CJ, Blaser MJ: Simple accurate PCR-based system for typing vaucolating cytotoxin alleles of Helicobacter pylori. J Clin Microbiol 1999, 37:2979-2982. 
27. Kelly SM, Pitcher MC, Farmery SM, Gibson GR: Isolation of Helicobacter pylori from feces of patients with dyspepsia in the United Kingdom. Gastroenterology 1994, 107:1671-1674.

28. Peek RM Jr, Miller GG, Tham KT, Perez-Perez Gl, Cover TL, Atherton JC, et al: Detection of Helicobacter pylori gene expression in human gastric mucosa. J Clin Microbiol 1995, 33:28-32.

29. Yamaoka Y, Kodama T, Kashima K, Graham DY, Sepulveda AR: Variants of the 3 ' region of the cagA gene in Helicobacter pylori isolates from patients with different H. pylori-associated diseases. J Clin Microbiol 1998, 36:2258-2263

30. Argent RH, Kidd M, Owen RJ, Thomas RJ, Limb MC, Atherton JC: Determinants and consequences of different levels of CagA phosphorylation for clinical isolates of Helicobacter pylori. Gastroenterology 2004, 127:514-523.

31. Hosmer DW, Lemeshow S (Eds): Applied Logistic Regression, JH. New York: Wiley Interscience Publication; 2000

32. Hatakeyama M: Anthorpological and clinical implications for structural diversity of the Helicobacter pylori CagA oncoprotein. Cancer Sci 2011, 102:36-43.

33. Rocha GA, Rocha AM, Silva LD, Santos A, Bocewicz AC, Queiroz R, Rde M, et al: Transmission of Helicobacter pylori infection in families of preschool-aged children from Minas Gerais, Brazil. Trop Med Int Health 2003, 8:987-991.

34. Kivi M, Johansson AL, Reilly M, Tindberg Y: Helicobacter pylori status in family members as risk factors for infection in children. Epidemiol Infect 2005, 133:645-652.

35. El-Omar EM, Carrington M, Chow WH, McColl KE, Bream JH, Young HA, et al: Interleukin-1 polymorphisms assocaited with increased risk of gastric cancer. Nature 2000, 404:398-402.

36. El-Omar EM, Rabkin CS, Gammon MD, Vaughan TL, Risch HA, Schoenberg $\mathrm{JB}$, et al: Increased risk of noncardia gastric cancer associated with porinfalmmatory cytokine genes polymorhisms. Gastroenterology 2003, 124:1193-1201.

37. Machado JC, Figueiredo C, Canedo P, Pharoah P, Carvalho R, Nabais S, et al: A proinflammatory genetic profile increases the risk for chronic atrophic gastritis and gastric carcinoma. Gastroenterology 2003, 125:364-371.

38. Rocha GA, Guerra JB, Rocha AMC, Saraiva IEB, da Silva DA, de Oliveira CA, et al: IL1RN polymorphic gene and cagA-positive status independently increase the risk of noncardia gastric carcinoma. Int J Cancer 2005, 115:678-683.

39. Figueiredo C, Machado JC, Pharoah P, Seruca R, Sousa S, Carvalho R, et al: Helicobacter pylori and interleukin 1 genotyping: an opportunity to identify high-risk individuals for gastric carcinoma. J Natl Cancer Instit 2002, 94:1680-1687.

doi:10.1186/1471-230X-12-107

Cite this article as: Queiroz et al: Higher frequency of cagA EPIYA-C Phosphorylation Sites in H. pylori strains from first-degree relatives of gastric cancer patients. BMC Gastroenterology 2012 12:107.

\section{Submit your next manuscript to BioMed Central and take full advantage of:}

- Convenient online submission

- Thorough peer review

- No space constraints or color figure charges

- Immediate publication on acceptance

- Inclusion in PubMed, CAS, Scopus and Google Scholar

- Research which is freely available for redistribution 